\title{
The Halting Problem
}

\author{
Nicholas Sobin*
}

\begin{abstract}
In Chomsky 2015 it is proposed that raising of a wh phrase from subject position is not possible unless $\mathrm{C}$ is deleted in the Narrow Syntax (NS), as seen in the that/Comp-trace Effect (C-tE). Evidence presented here indicates that the raising of a subject may allow and even require the overt presence of $\mathrm{C}$, pointing toward the conclusions that raising a subject is not related to $\mathrm{C}$ deletion, and that all $w h$ subjects raise. The alternative considered here is that the locus of phenomena such as the $\mathrm{C}$ tE may be the Sensory-motor (SM) component rather than NS. Taking anti-Comptrace phenomena into account, there appears to be a requirement that a subject extraction must be phonetically marked ('Subject Extraction Marking'--SEM), either by the subject itself being overt, or by the presence of an overt C. This paper proposes a possible SM analysis consisting of rules that account for the complexities of spelling out that including Doubly-filled Comp, the C-tE, and SEM.
\end{abstract}

Keywords. halting, that-trace effect, C-deletion, doubly-filled comp, SM, problems of projection, minimalist program

1. Introduction. “Halting” (Chomsky 2013, 2015; Rizzi 2015; Rizzi \& Shlonsky 2007) (a.k.a "Criterial Freezing") refers to the claim that certain syntactic objects are required to raise to a point in a syntactic structure where they are required to halt, and not raise any further. As Rizzi frames it, the "halting problem for subject movement" refers to questions surrounding the positioning of subjects--when must a subject move, and when must it halt? Halting is claimed to be manifest in the much discussed and analyzed Comp-trace Effect (C-tE) illustrated in (1).

a. Who did you say $\left[\mathrm{CP}\left(*^{\text {that }}\right)[\mathrm{TP} \mathrm{t}\right.$ read the book?

b. What did you say [CР (that) [те Mary read t ?

The fact that the presence of that in (1a) makes the sentence less acceptable for most speakers, is attributed in Chomsky 2015 to the $w h$ subject not being able to move beyond SPEC-T when a complementizer is present. ${ }^{1}$ In the presence of that, a wh phrase in SPEC-T must halt in that position, as all surface subjects are claimed to do. Only if that is deleted in the Narrow Syntax (NS) can such a wh phrase undergo further movement, allowing sentence (1a) without that. In contrast, object extraction is not so affected, as seen in (1b). The goals here are (i) to offer evidence that $\mathrm{C}$ deletion is not necessary for subject extraction from SPEC-T; (ii) to offer evidence suggesting that the $\mathrm{Ct}-\mathrm{E}$ and other phenomena related to $\mathrm{C}$ realization may instead be Sensory-motor (SM) phenomena; and (iii) to offer the possibility that there may be a process at

\footnotetext{
* Sincere thanks to Massimo Piattelli-Palmarini, Sam Epstein, Heidi Harley, Elly van Gelderen, and the audience members of the Arizona Linguistics Circles 8 and 9 for contributing to my understanding of the POP framework. This is not to say that they necessarily concur with the analysis and conclusions offered here. Any errors are solely the responsibility of the author. Author: Nicholas Sobin, The University of Texas at El Paso (njsobin@utep.edu)

${ }^{1}$ In this analysis, SPEC is claimed not to exist as a syntactically significant position. The term is used in the POP literature and here only for ease of exposition.
} 
work which is the polar opposite of C-deletion: "subject extraction marking"--the phonetic marking of a subject extraction.

2. The POP framework and $\mathbf{C}$ deletion. The analysis of the $\mathrm{C}$-tE in Chomsky 2015 is presented as a part of a different vision of minimalist syntax--"Problems of Projection" (POP). NS produces successions of two-member sets, which result in legitimate grammatical constructions only if each set is legible to the interfacing Conceptual-intentional (CI) and Sensory-motor (SM) components. Among other things, CI legibility requires that each set bear a label. Such labels are the product of an independent Labeling Algorithm (LA), which assigns a label to each merge set which CI will interpret. Briefly, if a head is merged with a non-head (a phrase) in the narrow syntax, LA takes the head as the label for the merged set. If two non-heads (phrases) are merged, then LA must find the head of each and determine if any features of these heads are in an agreement relation. If they are, then the agreeing feature(s) constitutes the label for that set. If there is no agreement, then one member may raise (internal Merge), leaving LA 'blind' to the raised element and the head of the other as determining the label. This is illustrated in (2).

$$
\begin{aligned}
& \text { a. }[\mathrm{H}, \mathrm{XP}]=\mathrm{LA}=>[\mathrm{H} \mathrm{H}, \mathrm{XP}] \\
& \text { b. }[\mathrm{XP}, \mathrm{YP}]=\mathrm{LA}=>\left[<_{\phi}>\mathrm{XP}, \mathrm{YP}\right] \text { (e.g. agreement between DP and TP) } \\
& \text { c. }[\mathrm{XP}, \mathrm{YP}]=\mathrm{LA}=>[\mathrm{XP}[\mathrm{Y}<\mathrm{XP}>, \mathrm{YP}]] \text { (non-agreement and raising) }
\end{aligned}
$$

In dealing with the halting problem, Chomsky 2015 considers the structure in (3).

$$
\text { [r who do you } \mathrm{V}^{*}{ }_{\varepsilon} \text { think [o } \mathrm{C}[\alpha \mathrm{t} \text { T [ } \beta \text { who read the book]]]] }
$$

The derivation is said to proceed as follows: First, $\mathrm{C}$ is merged with $\boldsymbol{\alpha}$, and $\mathrm{T}$ inherits the properties of $\mathrm{C}\left(=\left[{ }_{\delta} \mathrm{C}[\alpha \mathrm{T}[\beta\right.\right.$ who read the book $\left.\left.]]\right]\right)$. Next who is merged to SPEC-T from its predicate-internal subject position in $\beta$ ( $=[\delta \mathrm{C}[\alpha$ who $\mathrm{T}[\beta<\mathrm{who}>$ read the book $]]])$ ). $\mathrm{T}$ is a head, but is claimed to be too weak to label $\alpha$. However, the presence of a SPEC-T element strengthens $\mathrm{T}$, allowing $\boldsymbol{\alpha}$ to be labeled under agreement as $\left\langle\phi, \phi>\left(={ }_{{ }_{\delta}} \mathrm{C}\left[{ }_{<_{\phi}, \phi}>\right.\right.\right.$ who $\mathrm{T}\left[\beta{ }_{\beta}<\right.$ who $>$ read the book]]]]). Generally, the labeled complement of a phase head should transfer to CI and SM. Thus with $C$ in the structure as the active phase head, its complement phrase $\alpha$, now labeled $<\phi, \phi>(=\mathrm{TP})$ should transfer, but this creates the problem that who in SPEC- $\alpha$ would be included in the transferred material, making who inaccessible to further merge, with the further consequence that a sentence such as 'Who do you think read the book?' could not be derived.

At this point, it is proposed that $\mathrm{C}$ may delete from the structure, resulting in (4).

$$
\left.\left.\varnothing\left[<_{\phi, \phi}>\text { who } \mathrm{T}[\boldsymbol{\beta}<\text { who }>\text { read the book }]\right]\right]\right]
$$

As a consequence, $\mathrm{T}$ with its properties inherited from $\mathrm{C}$ becomes the 'active' phase head, and $\boldsymbol{\alpha}$ is said to retain its label $\langle\phi, \phi>$, but to 'de-phase'; it is now $\boldsymbol{\beta}$ rather than $\boldsymbol{\alpha}$ which is subject to 'transfer'. This leaves who accessible to further merge, possibly resulting in the sentence 'Who do you think read the book'.

In sum, the analysis just presented claims that the traditional view that that impedes an otherwise normal movement of a subject from SPEC-T is wrong. Instead, all subjects including $w h$ subjects are claimed to naturally halt in SPEC-T, and it is only an unusual rule of C-deletion which frees a subject to raise further.

3. Evidence of $\boldsymbol{W h}$ raising without $\mathrm{C}$ deletion. A number of facts and observations suggest that raising of a subject from SPEC-T is not related to the absence of $\mathrm{C}$. In fact, to the contrary, 
certain instances of subject raising appear to require the presence of $\mathrm{C}$. All of this renders the Cdeletion analysis unlikely.

3.1 ADVERB EFFECT RELATIVE CLAUSES. Culicover (1993:557) discusses the finding that the C$\mathrm{tE}$ is weakened/eliminated by the presence of an adverbial phrase following that, as in (5).

(5) Robin met the man who Leslie said [ ${ }_{\mathrm{CP}} t$ that *(for all intents and purposes) [TP $t$ was the mayor of the city.

The Adverb Effect not only compromises the C-tE as in (5), but also weakens/eliminates the restriction against "Doubly-filled Comp" (DFC) in sentences such as (6) and (7) (surveyed and analyzed in Sobin 2002). A wh phrase and a complementizer can both surface in CP when an adverbial phrase is present. First consider the object relative clauses in (6).

a. (I just saw) *a person [CР who that [тр Albert Einstein would admire _

b. (I just saw) a person [СР who that without a doubt [тР Albert Einstein would admire

c. (I just saw) *a person that (without a doubt) who Albert Einstein would admire

Although the presence of both an overt $w h$ and an overt $\mathrm{C}$ lead to unacceptability as in (6a), the DFC in (6b) with an adverbial expression is much more acceptable. The same holds true for subject relative clauses (Sobin 2002:543). The doubly-filled Comp in (7a) is clearly unacceptable, and this unacceptability is diminished/eliminated by the presence of an adverbial expression as in $(7 \mathrm{~b}){ }^{2}$

a. (I just saw) *a person [CP who that [TP _ could pass for Albert Einstein

b. (I just saw) a person [ $\mathrm{CP}$ who that without a doubt [TP_could pass for Albert Einstein

c. (I just saw) *a person that (without a doubt) who could pass for Albert Einstein

Of course, either who or that in (6b) and (7b) can be omitted, but when both appear, the subject wh must be to the left of $\mathrm{C}$ as (6b) vs (6c) and (7b) vs (7c) indicate. Subject and object relative pronouns raise uniformly to SPEC-C. Further, raising of a subject to SPEC-C as in (7b) takes place without deletion of that.

3.2 SUBJECT EXTRACTION REQUIRING C. It is not only the case that $\mathrm{C}$ may be present when a subject is extracted but further there are instances when $\mathrm{C}$ must be present for a subject extraction to take place. This can be demonstrated by first considering the parallel behavior of wh phrases and null OP, and then the behavior of $\mathrm{C}$ in subject vs. object relative clauses.

3.2.1 WH ISLANDS \& NULL OP. Beyond the preceding Adverb Effect relative clause data, the fact that $w h$ phrases generally raise to SPEC-C is further indicated by the existence of $W h$ Islands. It is broadly accepted that object $w h$ phrases as in (8) clearly raise to SPEC-C.

$$
[\text { CP What can [TP you see _ }]] \text { ? }
$$

A long-standing observation (starting with Ross 1967) is that a wh object cannot be raised over a $w h$ subject as in (9b).

\footnotetext{
2 The combination that-adverbial phrase is only possible when the adverbial appears with that in C position, as in (6-7). Adverbial phrases in other positions cannot combine with that, as in the following.

i) (I just saw) a person who could pass for Albert Einstein (*that) without a doubt

ii) (I just saw) a person who could pass (*that) without a doubt for Albert Einstein

iii) (I just saw) a person who could (*that) without a doubt pass for Albert Einstein
} 
a. [CP I asked [CP who $_{1}\left[\mathrm{TP}_{\mathrm{T}} \mathrm{t}_{1}\right.$ visited $\left.\left.\left.\mathrm{who}_{2}\right]\right]\right]$

b. ${ }^{*}\left[\mathrm{CP} \mathrm{Who}_{2}\right.$ did you ask [CP $\mathrm{Who}_{1}\left[\mathrm{TP}_{1} \mathrm{t}_{1}\right.$ visited $\left.\left.\left.\mathrm{t}_{2}\right]\right]\right]$

A standard account of the impossibility of (9b) is that who occupies the lower SPEC-C, blocking the possibility of raising $w h o_{2}$, on the assumption that who $o_{2}$ must pass through the lower SPEC-C to move any further. Consider next that data in (10).

a. ${ }^{*}$ The person who $_{2} \varnothing_{\mathrm{RC}} I$ asked [CP who $_{1}\left[\mathrm{TP}_{1} \mathrm{t}_{1}\right.$ visited $\left.\left.\mathrm{t}_{2}\right]\right]$

b. ${ }^{*}$ The person OP $\left(\right.$ that $\left._{\mathrm{RC}}\right)$ I asked [CP who $_{1}\left[\mathrm{TP}_{1} \mathrm{t}_{1}\right.$ visited $\left.\left.\mathrm{t}_{2}\right]\right]$

Just as $w h o_{1}$ blocks the merger of $w h o_{2}$ to the lower SPEC-C position in (10a), rendering it inaccessible to further raising, who likewise blocks the merger of OP to the lower SPEC-C position in (10b), also resulting in a $W H$ Island Effect. That is, OP, like a wh phrase, must merge to SPEC-C.

3.2.2 NULL OP \& REQUIRED THAT. Consider next the subject relative clauses in (11), and the object relative clauses in (12). ( ' $\emptyset_{\mathrm{RC}}$ ' represents the non-phonetic relative complementizer.

(11) a. The person [CP who $\emptyset_{\mathrm{RC}}[\mathrm{TP} \mathrm{t}$ saw the flying saucer $\left.]\right]$

b. The person [CP OP that ${ }_{R C}\left[{ }_{T P} t\right.$ saw the flying saucer ]]

c. ${ }^{*}$ The person [CP OP $\emptyset_{\mathrm{RC}}[\mathrm{TP} \mathrm{t}$ saw the flying saucer $\left.]\right]$

a. The person [CP who $\emptyset_{\mathrm{RC}}[\mathrm{TP}$ Mary saw t ]]

b. The person [CP OP that ${ }_{R C}[\mathrm{TP}$ Mary saw t]]

c. The person [CP OP $\emptyset_{\mathrm{RC}}[\mathrm{TP}$ Mary saw $\left.\mathrm{t}]\right]$

Assuming here that OP movement is simply wh movement (as indicated earlier), the acceptability of subject relative clauses is affected by the phonetic character of both the subject and the complementizer, but the acceptability of object RCs is not. As (11c) indicates, the subject and the complementizer cannot both be non-phonetic, a condition which object relative clauses do not observe (12c). As (11b-c) indicate, if the subject is OP, then the complementizer must be phonetic (an 'anti-C-tE'). It is the presence of overt that rather than its absence which is compatible with merging a subject OP to SPEC-C.

Taken together, the preceding observations lead to the conclusions that (i) wh subjects do not halt in SPEC-T but instead normally merge to SPEC-C, and (ii) C-deletion is not key to raising a subject beyond SPEC-T. To the contrary, on occasion, an overt $\mathrm{C}$ necessarily accompanies raising of a subject to SPEC-C.

4. Evidence of $\mathbf{C}$ realization as an $\mathbf{S M}$ phenomenon. The question to consider now is what form an alternative theory of complementizer realization (e.g. C-tE and DFC) might take within the dimensions of POP. The POP framework has the interesting property of strongly distinguishing where various types of phenomena should be dealt with. NS is centrally concerned with combining any pair of syntactic objects into a set via free Merge so as to feed the $\mathrm{CI}$ and SM components. Feature agreement and Case marking also take place within NS, the former being required for labeling. NS is not feature-driven. Selection, verifying that argument structure requirements are met, theta marking, etc. are the province of CI. Matters of phonetic realization are the province of SM. It is striking that a central consideration for subject extraction in both subject WHQs and subject RCs is the phonetic character of subject and complementizer. That phonetic realization is such a central factor leads naturally to the possibility that complementizer realization is phonetic rather than syntactic, suggesting a possible SM-based account. An SM approach would simplify NS, freeing it from the extra 
operations which destroy structure rather than build it and which cause an established phase to "dephase". Considerations of variation in the C-tE and of its acquisition seem to point to SM as a more likely source of C-tE/DFC phenomena.

4.1 VARIATION. Sobin (1983) reports significant variability in the acceptance of that-trace constructions by native English speakers in central Arkansas. Sobin (1987) reports similar results for native English speakers in Iowa and Illinois. Dye (1998), who worked with American informants in Arkansas, and Guest (2001) and Sobin (2002), who each worked with British informants, also report such variation. Early speculation was that this variation is dialectal, but later work (Cowart 2003) suggests that it is more general. Such fluctuation in the C-tE (dialectal or not) suggests that it is likely due to something other than 'principled' core syntactic derivation.

4.2 ACQUISITION. Thornton (1990) investigated that-trace constructions in English learners from 2;10 to 5;5 as a part of a larger study of wh -movement. One finding was that 11 (of 21) subjects who produced subject extractions used that $18 \%$ of the time as compared to $25 \%$ for object extractions. Some of her subjects produced that-trace constructions at a rate roughly comparable to the rate for object extractions with that.

As a part of a larger study of the acquisition of questions, McDaniel et al. (1995) investigated the acquisition of that-trace constructions by children from 2;11 to 5;7. Acceptability judgments were elicited in four separate sessions. In the four successive sessions, that-trace constructions were accepted by $78 \%, 59 \%, 58 \%$, and $73 \%$ of the subjects, respectively. This compares to other 'ungrammatical' constructions which were accepted by $24 \%, 21 \%, 14 \%$, and $18 \%$ of the subjects, respectively. Adult controls in the study accepted that-trace constructions at $20 \%$, while rejecting other 'ungrammatical' constructions $100 \%$ of the time (McDaniel et al. 1995:724).

Gathercole \& Montes (1997) investigated the degree to which the acquisition of that/quetrace constructions by bilingual learners of English and Spanish is comparable to that of monolingual learners of each language. The subjects were second-graders and fifth-graders in Miami. G\&M found that both monolingual and bilingual learners of English had difficulty recognizing C-tE ungrammaticality in English, though the monolingual and bilingual Spanish learners had much less difficulty recognizing the complementary effect with que (a requisite complementizer) in Spanish. G\&M's figure 2 (1997:85) shows English that-trace constructions being accepted at a level of approximately $90 \%$ by monolingual English second-graders and at a level of approximately $80 \%$ by monolingual English fifth-graders (who are normally $10+$ years old).

Together, these studies indicate that the C-tE varies in a way that other known ungrammaticals don't, and that beyond variability, that the $\mathrm{C}-\mathrm{tE}$ is acquired late. In the Gathercole \& Montes study, the fact that children up to 10 yrs allow subject extraction with that present in itself suggests that $\mathrm{C}$-deletion is not key to subject extraction. All of this further suggests a source for $\mathrm{C}$ realization other than 'principled' core syntactic derivation.

5. C realization as an $\mathbf{S M}$ phenomenon. Now, let us consider some of the possible dimensions of an SM-based account of C realization.

5.1 SUBJECT EXTRACTION MARKING: A FIRST APPROXIMATION. (13) shows the possible arrangements of key elements with $w h / O P$ subjects merged to SPEC-T.
a. RCs:
i. $\left[\right.$ that $_{\mathrm{RC}}[O P[\mathrm{~T} \ldots$

("the person that t saw Mary") 

ii. $\left[\varnothing_{\mathrm{RC}}[\right.$ who $[\mathrm{T} \ldots$
iii. $\left[\varnothing_{\mathrm{RC}}[O P[\mathrm{~T} \ldots\right.$
("the person who t saw Mary")
iv. $\left[\right.$ that $_{\mathrm{RC}}[$ who $[\mathrm{T} \ldots$
(“*the person t saw Mary")
("*the person who that saw Mary")
("Who did you say t saw Mary?")
(“*Who did you say that t saw Mary?”)

$\begin{array}{ll}\text { b. WHQs: } & \text { i. }\left[\varnothing_{\text {Decl }}[\text { who }[\mathrm{T} \ldots\right. \\ & \text { ii. }\left[\text { that }_{\text {Decl }}[\text { who }[\mathrm{T} \ldots\right.\end{array}$

(14) shows the results of uniform wh merger to SPEC-C.
a. RCs:
i. $\left[\right.$ that $_{\mathrm{RC}}\left[O P\left[\mathrm{~T} \ldots=>\left[O P\left[\right.\right.\right.\right.$ that $_{\mathrm{RC}}[<O P>[\mathrm{T} \ldots$
ii. $\left[\emptyset_{\mathrm{RC}}\left[\right.\right.$ who $\left[\mathrm{T} \ldots=>\left[\right.\right.$ who $\left[\emptyset_{\mathrm{RC}}[<w h o>[\mathrm{T} \ldots\right.$
iii. $\left[\emptyset_{\mathrm{RC}}\left[O P\left[\mathrm{~T} \ldots=\Rightarrow \quad \ldots\left[O P\left[\varnothing_{\mathrm{RC}}[<O P>[\mathrm{T} \ldots\right.\right.\right.\right.\right.$
iv. $\left[\right.$ that $_{\mathrm{RC}}\left[\right.$ who $\left[\mathrm{T} \ldots=>*\left[\right.\right.$ who $\left[\right.$ that $_{\mathrm{RC}}[<$ who $>[\mathrm{T} \ldots$
b. WHQs:

$$
\begin{aligned}
& \text { i. }\left[\emptyset _ { \text { Decl } } \left[\text { who } \left[\mathrm{T} \ldots=>\left[\text { who } \left[\emptyset_{\text {Decl }}[<w h o>[\mathrm{T} \ldots\right.\right.\right.\right.\right. \\
& \text { ii. }\left[\text { that } _ { \text { Decl } } \left[\text { who } \left[\mathrm{T} \ldots=>\quad *\left[\text { who } \left[\text { that }_{\text {Decl }}[<\text { who }>[\mathrm{T} \ldots\right.\right.\right.\right.\right.
\end{aligned}
$$

There is a possible generalization that unifies such $w h / O P$ movement in RCs and in WHQs: a subject extraction has to somehow be overtly marked, as in (15).

(15) Subject Extraction Marking (SEM):

An extracted subject must be marked phonetically. Either the subject or $\mathrm{C}$ must be phonetic.

Let us say that a $w h / O P$ subject can never remain in SPEC-T. Rather, merger of a $w h / O P$ subject or object to SPEC-C is uniform. But in order to license/legitimize the extraction of a subject, one of the elements in $\mathrm{CP}$ must be phonetic. The English facts suggest that either a phonetic subject or a phonetic $\mathrm{C}$ suffices to do this. The idea that $\mathrm{C}$ in relative clauses may serve as a subject extraction marker finds some support from the fact that naive native speakers routinely take that in relative clauses to be referential, like a pronoun. ${ }^{3}$ Even grammarians such as Fowler (1965:625-630) characterize that as a relative pronoun, along with who and which.

As a first approximation, we might say that in subject WHQs, where OP cannot be employed and the subject is always a phonetic $w h$ phrase, only a null C suffices, hence, the C-tE. If $\mathrm{OP}$ is employed as a subject in a $\mathrm{RC}$, then the condition on phonetic marking requires overt that. This is illustrated in (16).

$$
\begin{array}{llll}
\text { RCs: } & \text { a. }\left[\text { OP } \left[\mathrm{C}_{\mathrm{RC}}[<\mathrm{OP}>[\mathrm{T} \ldots\right.\right. & =\mathrm{SM}=> & {\left[\mathrm { OP } \left[\text { that }_{\mathrm{RC}}[<\mathrm{OP}>[\mathrm{T} \ldots\right.\right.} \\
& \text { b. }\left[\text { who } \left[\mathrm{C}_{\mathrm{RC}}[<w h o>[\mathrm{T} \ldots\right.\right. & =\mathrm{SM}=>\left[\text { who } \left[\emptyset_{\mathrm{RC}}[<w h o>[\mathrm{T} \ldots\right.\right. \\
\mathrm{ECP}: & \text { c. }\left[\text { who } \left[\mathrm{C}_{\mathrm{Decl}}[<w h o>[\mathrm{T} \ldots\right.\right. & =\mathrm{SM}=>\left[\text { who } \left[\emptyset_{\mathrm{Dec} / \mathrm{Q}}[<w h o>[\mathrm{T} \ldots\right.\right.
\end{array}
$$

In (16a), where OP is a subject, condition (15) requires that $C_{R C}$ must be pronounced as that. In (16b) and (16c), where the subject is a $w$ h phrase, $\mathrm{C}$ can be rendered as phonetically null. This condition on the phonetic marking of subjects is cross-cut by the more general ban in modern English on allowing more than one phonetic element to surface in the CP layer, the often discussed 'Doubly-filled Comp Filter' (DFC) (Keyser 1975). So the tension with subjects is between requiring phonetic marking on the one hand, and not allowing over-marking on the other.

Given that the SEM condition (15) is not syntactic but phonetic, a condition imposed in $\mathrm{SM}$, then all of the derivations suggested in (14) would proceed syntactically, and be intelligible,

\footnotetext{
${ }^{3}$ This is not to say that $\mathrm{C}$ 'becomes' the subject or actually gains any pronominal status. It remains only a $\mathrm{C}$, but the fact that it is involved in such marking leads speakers to the impression that it is/may be referential/pronominal.
} 
with some of them 'sounding funny' (though studies of variation in the $\mathrm{C}$-tE, as well as the Adverb Effect compromising the $\mathrm{C}$-tE and allowing DFC in relative clauses, show that they don't always sound funny).

Thus far, it looks as though condition (15) might account directly for the C-tE. However, Adverb Effect constructions such as (5), (6b), and (7b) (repeated here) indicate that the picture is not this simple.

(5) Robin met the man who Leslie said [CР $t$ that *(for all intents and purposes) [тр $t$ was the mayor of the city.

(6) b. (I just saw) a person [ $\mathrm{CP}$ who that without a doubt [тр Albert Einstein would admire

(7) b. (I just saw) a person [ $\mathrm{CP}$ who that without a doubt [TP _ could pass for Albert Einstein

If the writing of $\mathrm{C}_{\mathrm{RC} / \mathrm{Decl}}$ as that were guided exclusively by SEM, then there would be no means of generating that in these Adverb Effect constructions. Beyond the required marking of a subject extraction, there must be other instances of that which are freely allowed.

5.2 SEM vs DFC vs C-tE. Further light on SEM ( as well as on C-tE and DFC) can be shed by considering the sequence 'that-AvP' more closely. First, that-AvP appears to form a constituent, as indicated by the fact that it may coordinate, as in (17). (Sobin 2002)

$$
\begin{aligned}
& \text { a. John claimed that in the last election and that in all earlier ones ballot boxes were } \\
& \text { stuffed. } \\
& \text { b. They say that with some work and that with a little luck Sian will win the } \\
& \text { championship. }
\end{aligned}
$$

That this is not Right-node-raising (RNR) can be seen by considering RNR constructions such as those in (18).
a. The lawyers claimed that on July 4 - and Mary testified that on July 5 - Bill was in Rhyl.
b. *The lawyers claimed that on July 4 - and the lawyers claimed that on July 5 - Bill was in Rhyl.

RNR constructions require considerable contrast between the contributing clauses, which (18b) lacks. However, the same degree of contrast seen in (18b) is also present but acceptable in (19).

(19) The lawyers claimed that on July 4 and that on July 5 Bill was in Rhyl.

These considerations suggest that that-AvP is coordinatable and therefore a constituent.

Second, that-AvP only occurs in $\mathrm{C}$ position. While the AvP alone may appear in a variety of positions in the sentence, the presence of that is only acceptable where $\mathrm{C}$ would appear (see footnote 2). Thus, that in that-AvP is a $\mathrm{C}$, and not a 'phantom' particle accompanying AvP.

Third, the C-tE and the DFC restriction are each blind to the Ø/that character of $\mathrm{C}$ when it is a part of 'C-AvP'. C-tE should suppress that in (5), but it doesn't, and the DFC restriction should disallow the co-occurrence of who and that in (7b), as well as in (6b), but it also doesn't. However, the $\mathrm{C}$ in the $\mathrm{C}$-AvP constituent is visible to SEM, since this $\mathrm{C}$ necessarily undergoes spelling out as that, as in (20).

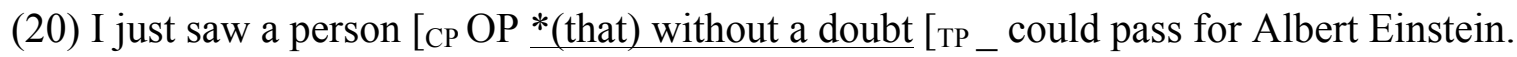

Whether or not the AvP is present, the sentence is unacceptable if that in (20) is not spelled out. 
So it seems that SEM stands apart from both the DFC restriction and the C-tE in that SEM is able to 'see' and regulate the phonetic character of a $\mathrm{C}$ in [C-AvP], whereas the DFC restriction and the $\mathrm{C}$-tE restriction cannot.

Consider next the properties of the DFC restriction, stated informally in (21).

(21) DFC Restriction (ATB) (ModE):

The CP layer must not contain both overt $w h$ and overt $\mathrm{C}$.

The DFC restriction holds not just for subject extractions, but 'across-the-board'--for all wh extractions, disallowing any DFC. It is 'known' and employed early on in acquisition--children acquiring modern English don't produce DFCs. Further, the DFC restriction must be applied only after $w h$ is raised to its final/surface position. Otherwise good object extractions with that as in (22) would be barred just as a genuine DFC violation as in (23) is.

Who did you say [CP $<$ who $>$ that [TP Mary saw_?

*The person[ Се who that [те Mary saw _...

That DFCs are not disallowed 'in principle' is indicated by the fact that DFCs were apparently common in Middle English. Typical examples are (24).

(24) a. The Tale Of The Wife Of Bath, Chapter 31: Line 257

Looke who that is moost vertuous alway,

Find him who is most virtuous alway,

b. The Second Nun's Tale, Chapter 47: Line 33

I have an Aungel which that loveth me,

I have an angel lover that loves me,

c. The Manciple's Tale Of The Crow, Chapter 51: Line 36

Which that he lovede moore than his lyf;

Whom he loved better than he loved his life,

(http://www.canterburytales.org/canterbury tales.html)

Perhaps the DFC restriction is the 'unmarked' case, assumed operative unless there is evidence in the language to the contrary (as in Middle English).

The C-tE might be informally stated as in (25).

(25) The C-tE Restriction:

The CP layer initially involved in a subject extraction must contain only one phonetic representative of the subject, a $w h$ element or C.

The C-tE also has a distinct set of properties. Like SEM and unlike the DFC restriction, it is concerned only with subjects and the phonetic character of C. Also, unlike DFC, it is concerned with a wh copy of an extracted subject, not a surface phonetic form. Like the DFC restriction, and unlike SEM, while it suppresses phonetic representation (of C), it cannot affect that within a that-AvP constituent. Finally, as shown earlier, it is acquired late, long after children are able to produce both subject and object extractions.

In sum, the problem now is one of guaranteeing (i) marking of subject extractions, (ii), sufficient 'over-generation' of that to allow for its possible appearance in a range of Adverb Effect constructions, and (iii) the suppression of that elsewhere in compliance with the DFC restriction and the $\mathrm{C}-\mathrm{tE}$. 
5.3 A SYSTEM OF THAT REALIZATION. Perhaps in SM spellout, rather than suppressing something initially marked for phonetic realization, certain Cs are marked for 'zero' phonetics, allowing the Cs not so marked to be optionally or obligatorily spelled out. With this in mind, consider the following possible analysis of that realization.

$\mathrm{SM}$ realization of $\mathrm{C}_{\mathrm{RC} / \mathrm{Decl}}$ :

a. The C-tE: $\mathrm{C}_{\mathrm{RC} / \mathrm{Decl}}=\mathrm{SM}=>\varnothing /\left[\mathrm{CP}<\right.$ who $>\ldots\left[<_{\phi, \phi}><\right.$ who $>\ldots$

(NB: this misses $\left.\left[\mathrm{C}_{\mathrm{RC} / \text { Decl }}-\mathrm{AvP}\right]\right)$

b. The DFC Restriction (ModE): $\mathrm{C}_{\mathrm{RC} / \mathrm{Decl}}=\mathrm{SM}=>\varnothing /\left[\mathrm{CP} \mathrm{WH} \_\left[<_{\phi}, \phi \cdots\right.\right.$

(NB: this also misses $\left.\left[\mathrm{C}_{\mathrm{RC} / \mathrm{Decl}}-\mathrm{AvP}\right]\right)$

c. That realization: $\mathrm{C}_{\mathrm{RC} / \mathrm{Decl}}=\mathrm{SM}=>$ ' that'

(i) is required for a phonetically unmarked subject extraction (SEM) (i.e. $/\left[\mathrm{CP} \mathrm{OP} \ldots \ldots\left[<_{\phi, \phi}<\mathrm{OP}>\right.\right.$ ), and

(ii) is optional for other $\mathrm{C}_{\mathrm{RC} / \mathrm{Decl}}$.

This analysis does not 'over generate' and remove instances of that, but instead can spell out any C which has not been marked for 'zero' spellout. SM rules (26a) and (26b) can only see and mark as ' $\varnothing$ ' a simple $C$ in the stated environments. Given the earlier data on the acquisition of the $\mathrm{C}$-tE, rule (26a) is apparently acquired late, and not crucial to syntactic derivation. Rule (26b) appears to always be active in ModE. Rule (26ci) requires that any $\mathrm{C}$ following a null subject be spelled out as that, the SEM requirement. Unlike rules (26a-b), this includes $\mathrm{C}_{\mathrm{RC} / \mathrm{Decl}}$ in $\left[\mathrm{C}_{\mathrm{RC} / \mathrm{Dec}}-\mathrm{AvP}\right]$. There are other possibilities. Further answers await further work on what specific mechanisms make up SM and how they should operate.

6. A possible bases for variable and late establishment of C-tE. SEM says 'A subject extraction must be marked (with that if the subject is null)' and the C-tE restriction says 'Don't over-mark a subject extraction'--that is, suppress that. Perhaps the variability of C-tE is partly due to two competing processes imposing 'opposite' pressures on the spelling of that in a subject extraction. Further, the C-tE restriction may involve looking at a $w h$ copy in SPEC-C as well as another wh copy in SPEC-T, the SM indicator that a SUBJ extraction is at issue. The calculation thus may involve abstract (non-surfacing) elements. In contrast, the DFC restriction is simply looking at two overt elements in $\mathrm{CP}$, not differentiating subject, object, or adjunct extraction. In contrast to $\mathrm{C}$-tE, the DFC restriction looks 'surface-obvious'.

7. Summary remarks. An implication of this analysis for the narrow syntax is that 'SPEC-T' may not have any special status in regard to "halting". Apparent halting as manifest in the C-tE is a consequence of SM spellout, and is not related to the operation of the syntax. Any $w h$ phrase or OP in SPEC-T moves on, at least to its local SPEC-C. The POP analysis receives support from this analysis in that the narrow syntax is now purely 'constructive' and not 'destructive'. In avoiding the need for $\mathrm{C}$-deletion and de-phasing, the narrow syntax is simplified.

Also, there remains the more fundamental question of why SEM, the C-tE, and the DFC restriction should exist at all. Earlier attempts at principled explanations such as the ECP have fallen away completely as the theoretical perspective has evolved. If the phenomena considered here are indeed SM phenomena, then perhaps a principled explanation awaits the further development of a theory of the SM component. Clearly there is much more to learn about the operation of SM, about how this approach might extent to other Cs in English, and about the application of this approach to subject extraction in other languages. 
References

Chomsky, Noam. 2013. Problems of projection. Lingua 130. 33-49.

Chomsky, Noam. 2015. Problems of projection: extensions. In Domenico, Elisa Di, Cornelia Hamann and Simona Matteini (eds.), Structures, strategies and beyond: Studies in honour of Adriana Belletti. 1-16. Amsterdam: John Benjamins.

Culicover, Peter. 1993. Evidence against ECP accounts of the that-t effect. Linguistic Inquiry 24. 557-561.

Fowler, H.W. 1965. Fowler's modern English usage, $2^{\text {nd }}$ ed. (revised by Sir Ernest Gowers) Oxford: Oxford University Press.

Gathercole, Virginia C. \& Montes, Cecilia (1997). That-trace effects in Spanish- and Englishspeaking monolinguals and bilinguals. In A. T.Perez-Leroux \& W. R.Glass (eds.), Contemporary perspectives on the acquisition of Spanish. Vol. 1: Developing grammars. 75-95. Cascadilla Press: Somerville, MA.

Keyser, S. J. 1975. A Partial History of the Relative Clause in English. In J. Grimshaw (ed.), Papers in the History and Structure of English. 1-33. Amherst, Mass: Univ. of Massachusetts.

McDaniel, Dana, Chiu, Bonnie \& Maxfield, Thomas. 1995. Parameters for wh-movement types: evidence from child language. Natural Language \& Linguistic Theory 13. 709753.

Rizzi, Luigi. 2013. Cartography, criteria and labeling. Ms., Universities of Siena and Geneva.

Rizzi, Luigi., and Ur Shlonsky. 2007. Strategies of Subject Extraction. In HansMartin Gärtner and Uli Sauerland (eds.), Interfaces +Recursion = Language? Chomsky's Minimalism and the View from Syntax-Semantics. 115-160. Berlin: Mouton de Gruyter.

Rizzi, Luigi. 2015. Notes on labeling and subject positions. In Domenico, Elisa Di, Cornelia Hamann and Simona Matteini (eds.), Structures, strategies and beyond: Studies in honour of Adriana Belletti. 17-46. Amsterdam: John Benjamins.

Ross, John R. 1967. Constraints on variables in syntax. Doctoral dissertation. M.I.T.

Sobin, Nicholas. 1983. "On COMP-Trace Constructions in English," 58th Annual Meeting of the Linguistic Society of America, Minneapolis, Minn.

Sobin, Nicholas. 1987. The Variable Status of Comp-Trace Phenomena. Natural Language \& Linguistic Theory 5.1. 33-60.

Sobin, Nicholas. 2002. The Comp-trace Effect, the Adverb Effect and Minimal CP. Journal of Linguistics 38: 527-560.

Thornton, Rosalind. 1990. Adventures in long-distance moving: the acquisition of wh-questions. Ph.D. dissertation, University of Connecticut. 